\title{
The Clinical Characteristics and Risk Factors for Poor Prognosis Among HIV Patients with Talaromyces Marneffei Bloodstream Infection
}

Jianjun Sun

Shanghai Public Health Clinical Center

Weiwei Sun

Shanghai Public Health Clinical Center

Yang Tang

Shanghai Public Health Clinical Center

Renfang Zhang

Shanghai Public Health Clinical Center

Li Liu

Shanghai Public Health Clinical Center

Yinzhong Shen

Shanghai Public Health Clinical Center

Jiangrong Wang

Shanghai Public Health Clinical Center

Jun Chen

Shanghai Public Health Clinical Center

Tangkai Qi

Shanghai Public Health Clinical Center

Zhenyan Wang

Shanghai Public Health Clinical Center

\section{Wei Song}

Shanghai Public Health Clinical Center

Yixiao Lin

Shanghai Public Health Clinical Center

Shuibao Xu

Shanghai Public Health Clinical Center

Hong-zhou Lu ( $\square$ luhongzhou@fudan.edu.cn )

Shanghai Public Health Clinical Center 
Keywords: HIV infection, AIDS, Talaromyces marneffei, blood stream infection, prevalence, clinical characteristics, poor prognosis, risk factors

Posted Date: January 19th, 2021

DOI: https://doi.org/10.21203/rs.3.rs-147633/v1

License: (c) (1) This work is licensed under a Creative Commons Attribution 4.0 International License. Read Full License 


\section{Abstract}

Background Talaromyces marneffei(TM) bloodstream infection is common in AIDS patients with extreme immunodeficiency in Southeast Asia and South China, however, clinical case study on TM bloodstream infection is scarce. We retrospectively analyze the clinical characteristics of TM bloodstream infection in hospitalized AIDS patients and determine the outcomes of hospitalization after diagnosis in our hospital over the past 5 years.

Methods From January 2015 to July 2020, cases of TM detected by blood culture in patients admitted to our center were sorted and analyzed. The admission complaints, blood cells, biochemistry, CD4/CD8 count and 1,3- $\beta$-D-glucan, procalcitonin, CRP level on the day of blood culture test, and outcomes during hospitalization were analyzed. Logistic regression analysis was performed for the risk factors for poor prognosis. Spearman correlation analysis was used to analyze the correlation between peripheral blood cells, albumin and the time required for TM to become positive in blood culture. The difference was statistically significant when the $P$ value was $<0.05$.

Results A total of 87 patients were collected, with a median age of 34 years, a median hemoglobin of 94 $\mathrm{g} / \mathrm{L}$ and CD 4 count of $7 / \mu \mathrm{l}$. The rate of TM bloodstream infection among all in-hospital patients increased from $0.99 \%$ in 2015 to $2.09 \%$ in 2020 (half year). Patients with TM bloodstream infection with a CD8 count $<200 / \mu \mathrm{l}$ had a 12.6 -fold higher risk of poor prognosis than those with a CD8 count $>200 / \mu \mathrm{l}$ $(p=0.04)$, and those with 1,3- $\beta$-D-glucan $<100 \mathrm{pg} / \mathrm{mL}$ had a 34.9 -fold higher risk of poor prognosis than those with 1,3-beta-D-glucan $>100 \mathrm{pg} / \mathrm{mL}(\mathrm{p}=0.01)$.

Conclusions TM bloodstream infection is becoming more common in advanced AIDS patients in endemic

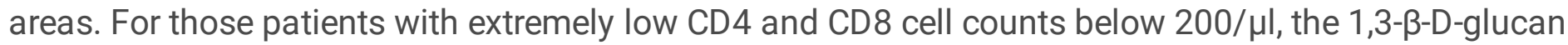
$<100 \mathrm{pg} / \mathrm{mL}$ are with an increased risk of poor prognosis.

\section{Background}

AIDS patients are susceptible to multiple opportunistic infections at the late stage, especially when the CD4 count is below $50 / \mu l[1,2]$. The spectrum of bloodstream infection varies among people living with AIDS in different geographical settings[3]. Talaromyces marneffei (formerly Penicilliosis marneffei) is endemic in Southeast Asia[4], Northeastern India[5], and Southern China[6]. The first natural human case of Talaromycosis (Penicillosis) was reported in 1973 and involved an American minister with Hodgkin's disease who lived in Southeast Asia[7]. TM was first reported in mainland China by Z.L. Deng in 1984[8] and in Vietnam by T.V. Hien in 2001[9]. Recently, TM has become an emerging pathogen in immunocompromised patients in mainland China[7]; furthermore, the number of confirmed cases of TM is increasing quickly in mainland China[10]. The incidence rates of TM infection range from 4-14\%, with an associated mortality of $10-30 \%[11]$. Reports of TM disease are common in the AIDS population in the late stage. A meta-analysis [12] showed that the prevalence of TM among HIV patients in China ranged from $0.2 \%$ (95\% Cl: $0.1-0.5 \%)$ to $26.5 \%$ (95\% Cl: $16.2-43.5 \%)$. South China had the highest prevalence, 
estimated at $15.0 \%$ (95\% Cl: $11.0-20.4 \%)$, while Southwest China had the lowest prevalence, estimated at $0.3 \%[13]$. It is estimated that there will be 4,951 TM cases per year in patients with AIDS in southern China by 2050, and the endemic areas are increasing[12]. The disease is mostly confirmed in the lungs and skin and is related to TM contact by inhalation or direct contact[14, 15]. However, in clinical settings, because the onset of the disease is relatively insidious and mild, the clinical symptoms are not very typical, and patients often experience delayed diagnosis or misdiagnosis by doctors who are not familiar with the symptoms of TM disease. Although they are finally diagnosed with TM, there are multiple organ lesions, such as superficial lymphadenopathy, abdominal pain, hepatosplenomegaly, mediastinal lymph node enlargement, bone marrow involvement and hematopenia[16]. TM bloodstream infection is a kind of TM disease, especially in AIDS patients with extreme immunodeficiency; however, clinical case studies on TM bloodstream infection are scarce. Our hospital is a referral center for AIDS patients in East China and many AIDS patients were admitted in hospital every year. The aim of this study was to retrospectively analyze the clinical characteristics of TM bloodstream infection in hospitalized AIDS patients and determine the outcomes of hospitalization after diagnosis in our hospital over the past 5 years.

\section{Methods}

The design and setting of the study

Retrospectively collected from January 1st 2015 to July 31th 2020, cases of TM detected by blood culture in patients admitted to the Shanghai Public Health Clinical Center (SPHCC) were sorted and analyzed. Electronic medical records of HIV-infected patients diagnosed with TM bloodstream infection (defined by a culture positive for TM from patient blood) were searched. Information including place of birth or long-term residence, presenting complaints and physical examinations (fever, umbilical fovea-like rash[17], and superficial lymphadenopathy), and laboratory tests (routine blood test, biochemistry, procalcitonin, CD4/CD8 T-cell count, CRP and outcomes during hospitalization) were analyzed. Blood culture tests were performed on patients with fever, loss of weight, lymphadenopathy or other symptoms need considering infection on the time of getting admission, and routine blood tests and tests for biochemistry, cellular immune function, procalcitonin and CRP were measured at the same time as blood culture. The patients were divided into a survival group and a poor prognosis group (death or having given up treatment due to advanced severe disease and being discharged from the hospital before death) according to their final clinical outcomes during the hospital admission.

SPHCC is the designated hospital for HIV patients in Shanghai municipality and is also a tertiary referral hospital for refractory and complicated HIV-infected cases in China. Cultures of clinical specimens were established on Sabouraud's dextrose agar at $25^{\circ} \mathrm{C}$ and $37^{\circ} \mathrm{C}[18]$.

\section{The characteristics of participants}

Among 8621 cases (from January 1st 2015 to July 31th 2020) admitted to SPHCC, there were 662 positive blood culture results and including 87 cases with TM bloodstream infection. 
The rank sum test was used for the comparison of demographics and clinical characteristic data between the two groups; chi-square analysis was used for the comparison of categorical variables. The predictors included in the multivariate model were selected based on a significance level of $p<0.1$ in the univariate analyses. The confounding factors retained in the multivariate model were serum procalcitonin (>0.60 ng/mL), CD8 count level $(<200 / \mu \mathrm{l}), 1,3$-beta-D-glucan $(<100 \mathrm{pg} / \mathrm{mL})$ and blood urea nitrogen level $(>4 \mathrm{mmol} / \mathrm{L})$. Spearman correlation analysis was used to analyze the correlation between peripheral blood cells, albumin and the time required for TM to become positive in blood culture. The difference was statistically significant when the $P$ value was $<0.05$. Data analysis was conducted using IBM SPSS version 20.0 (IBM SPSS, Inc., Armonk, NY, USA).

\section{Results}

Case distribution and trends in TM bloodstream infection

Among 8621 cases (from January 1st 2015 to July 31th 2020) admitted to SPHCC, the rate of TM bloodstream infection among all in-hospital patients was $13(0.99 \%)$ in 2015, and in 2019, it grew to 18 $(1.01 \%)$. Since July 2020 , the rate was $2.09 \%$. Because SPHCC is a referral hospital in China, all TM bloodstream infection cases were scattered throughout many provinces, Zhejiang (24 cases) and Jiangxi (13 cases) were the two provinces with the largest number of TM bloodstream infection cases in this analysis.

The comparison of clinical and laboratory features between the two groups with different clinical outcomes

The median age of patients with TM bloodstream infection was 34 years, the median hemoglobin level was $94 \mathrm{~g} / \mathrm{L}$, and the median CD4 count was $7 / \mu \mathrm{l}$. The median time required for TM culture conversion(from taking blood culture to TM identified) was 8 days. The blood urea nitrogen level, procalcitonin and CRP in the poor prognosis group were significantly higher than those in the survival group; the peripheral blood CD8 count, 1,3- $\beta$-D-glucan, and serum albumin in the poor prognosis group were significantly lower than those in the survival group; the count levels of hemoglobin and CD4 in the poor prognosis group were lower than those in the survival group, but the difference was not significantly different. There was no significant difference in age or gender rate between the two groups. Among the 87 cases with TM bloodstream infection, there were 10 cases of NTM disease ( 6 cases of pulmonary NTM disease, 3 cases of NTM blood infection, 1 case of intestinal NTM disease); 10 cases of PCP; 9 cases of oral candidiasis; 8 cases of CMVR; 5 cases of combined tuberculosis infection, including 3 cases of tuberculosis, 1 case of lymphotuberculosis, 1 case of tuberculous pleurisy; and 1 case of cryptococcal meningitis. For patients with poor prognosis, the median length of hospital stay was 5 days, with a minimum of 1 day and a maximum of 22 days; for patients with normal discharge, the median length of hospital stay was 22 days (See Table 1). 
Table 1

The demographics and clinical characteristic of TM bloodstream infection patients

\begin{tabular}{|c|c|c|c|c|c|}
\hline $\begin{array}{l}\text { Demographics and } \\
\text { clinical data }\end{array}$ & $\begin{array}{l}\text { Normal } \\
\text { range }\end{array}$ & $\begin{array}{l}\text { Total cases }(\mathrm{n} \\
=87)\end{array}$ & $\begin{array}{l}\text { Survival cases } \\
(n=72)\end{array}$ & $\begin{array}{l}\text { Poor prognosis } \\
(n=15)\end{array}$ & $\begin{array}{l}P \\
\text { value }\end{array}$ \\
\hline Age (years) & -- & $\begin{array}{l}34.0(28.0- \\
44.0)\end{array}$ & $\begin{array}{l}33.5(27.3- \\
43.0)\end{array}$ & $\begin{array}{l}37.0(30.0- \\
46.0)\end{array}$ & 0.71 \\
\hline Male (\%) & - & $81(93 \%)$ & $68(94 \%)$ & $13(87 \%)$ & $0.28^{*}$ \\
\hline WBC $\left(* 10^{9} / \mathrm{L}\right)$ & $3.5 \rrbracket 9.5$ & $3.4(2.4-5.1)$ & $3.4(2.4-4.9)$ & $4.5(2.1-8.1)$ & 0.57 \\
\hline Neutrophil $(* 109 / L)$ & $1.8 \rrbracket 6.3$ & $2.9(1.7-4.2)$ & $2.9(1.7-4.0)$ & $2.4(1.6-6.5)$ & 0.65 \\
\hline Hemoglobin $(\mathrm{g} / \mathrm{L})$ & $115 \rrbracket 150$ & $94(81-107)$ & $95(81-107)$ & $86(80-104)$ & 0.30 \\
\hline Platelet (*109/L) & $125 \llbracket 350$ & $100(66-155)$ & $\begin{array}{l}99.5(72.3- \\
149.3)\end{array}$ & 103(23-198) & 0.60 \\
\hline \multirow[t]{2}{*}{ CD4 count (/ul) } & \multirow[t]{2}{*}{$410 \otimes 1590$} & $7(4-19)$ & $9(4-21)$ & $5(3-12)$ & \multirow[t]{2}{*}{0.05} \\
\hline & & $\mathrm{N}^{\dagger}=84$ & $\mathrm{~N}^{\dagger}=71$ & $N^{\dagger}=13$ & \\
\hline \multirow[t]{2}{*}{ CD8 count (/ul) } & \multirow[t]{2}{*}{$190 \otimes 1140$} & \multirow{2}{*}{$\begin{array}{l}202(98-336) \\
N=82\end{array}$} & $223(106-384)$ & $122(57-186)$ & \multirow[t]{2}{*}{0.01} \\
\hline & & & $N=70$ & $N=12$ & \\
\hline \multirow[t]{2}{*}{ Ratio of CD4/CD8 } & \multirow[t]{2}{*}{$0.9 \llbracket 3.6$} & \multirow[t]{2}{*}{$\begin{array}{l}0.04(0.02- \\
0.10) N=82\end{array}$} & $\begin{array}{l}0.04(0.02- \\
0.10)\end{array}$ & $\begin{array}{l}0.06(0.03- \\
0.10)\end{array}$ & \multirow[t]{2}{*}{0.74} \\
\hline & & & $N=70$ & $N=12$ & \\
\hline \multirow[t]{2}{*}{ BUN (mmol/L) } & \multirow[t]{2}{*}{$2.6 \bigotimes 7.5$} & \multirow{2}{*}{$\begin{array}{l}4.1(3.2-6.0) \mathrm{N} \\
=86\end{array}$} & $4.0(3.1-5.4)$ & $6.6(4.0-12.2)$ & \multirow[t]{2}{*}{0.001} \\
\hline & & & $N=72$ & $N=14$ & \\
\hline \multirow[t]{2}{*}{ Serum Albumin (g/L) } & \multirow[t]{2}{*}{$40 \bigotimes 55$} & $27(23-31)$ & $28(24-31)$ & $25(22-28)$ & \multirow[t]{2}{*}{0.07} \\
\hline & & $N=86$ & $N=72$ & $N=14$ & \\
\hline РCT (ng/mL) & $0 \otimes 0.05$ & $\begin{array}{l}0.63(0.21- \\
1.75) N=74\end{array}$ & $\begin{array}{l}0.50(0.19- \\
1.65) \mathrm{N}=63\end{array}$ & $\begin{array}{l}1.09(0.62- \\
15.45) \mathrm{N}=11\end{array}$ & 0.04 \\
\hline \multirow[t]{2}{*}{$\mathrm{CRP}(\mathrm{mg} / \mathrm{L})$} & \multirow[t]{2}{*}{$0 \otimes 10$} & $54(26-88)$ & $44(24-81)$ & $71(53-111)$ & \multirow[t]{2}{*}{0.03} \\
\hline & & $N=76$ & $N=63$ & $N=13$ & \\
\hline \multirow[t]{2}{*}{$\mathrm{BDG}(\mathrm{pg} / \mathrm{mL})$} & \multirow[t]{2}{*}{$<60$} & \multirow{2}{*}{$\begin{array}{l}194(48-264) \\
N=74\end{array}$} & $205(101-287)$ & $54(10-222)$ & \multirow[t]{2}{*}{0.01} \\
\hline & & & $N=62$ & $N=12$ & \\
\hline
\end{tabular}

* By Fihser exact test; Others by Manny-Whitney test; $+\mathrm{N}$, means some of the cases with the clinical data and being collected in this analysis. WBC: White blood cell; BUN: Blood urea nitrogen; PCT:

Procalcitonin; CRP: C-reactive protein; BDG: 1,3- $\beta$-D-Glucose; TB: Tuberculosis; NTM: Nontuberculous mycobacteria; CMVR: Cytomegalovirus rentinitis; PCP: Pneumocystis carinii pueumonia; PCP:

Pneumocystis jirovecii pueumonia. 


\begin{tabular}{|c|c|c|c|c|c|}
\hline $\begin{array}{l}\text { Demographics and } \\
\text { clinical data }\end{array}$ & $\begin{array}{l}\text { Normal } \\
\text { range }\end{array}$ & $\begin{array}{l}\text { Total cases }(\mathrm{n} \\
=87)\end{array}$ & $\begin{array}{l}\text { Survival cases } \\
(n=72)\end{array}$ & $\begin{array}{l}\text { Poor prognosis } \\
(n=15)\end{array}$ & $\begin{array}{l}P \\
\text { value }\end{array}$ \\
\hline Fever & - & $81(93.1 \%)$ & $67(93.1 \%)$ & $14(93.3 \%)$ & $0.97^{\star}$ \\
\hline Rash & - & $31(35.6 \%)$ & $26(36.1 \%)$ & $5(33.3 \%)$ & $0.84^{*}$ \\
\hline $\begin{array}{l}\text { Lymphnode } \\
\text { enlargement }\end{array}$ & - & $25(28.7 \%)$ & $21(29.2 \%)$ & $4(26.7 \%)$ & $0.85^{*}$ \\
\hline TB coinfection & - & $5(5.7 \%)$ & $5(6.9 \%)$ & $0(0 \%)$ & $0.29^{*}$ \\
\hline NTM disease & - & $10(11.5 \%)$ & $9(12.5 \%)$ & $1(6.7 \%)$ & $0.52^{\star}$ \\
\hline CMVR & - & $8(9.2 \%)$ & $8(11.1 \%)$ & $0(0 \%)$ & $0.18^{*}$ \\
\hline PCP & - & $10(11.5 \%)$ & $8(11.1 \%)$ & $2(13.3 \%)$ & $0.81^{*}$ \\
\hline $\begin{array}{l}\text { Cryptococcal } \\
\text { meningitis }\end{array}$ & - & $1(1.1 \%)$ & $1(1.4 \%)$ & $0(0 \%)$ & $0.65^{*}$ \\
\hline Oral candiditis & - & $9(10.3 \%)$ & $5(6.9 \%)$ & $4(26.7 \%)$ & $0.02^{*}$ \\
\hline Hospital stay (days) & - & $21(16-25)$ & $22(19-26)$ & $5(3-13)$ & $<0.0001$ \\
\hline $\begin{array}{l}\text { Culture conversion } \\
\text { days }\end{array}$ & - & $8(6-9)$ & $8(6-9)$ & $6(5-9)$ & 0.12 \\
\hline \multicolumn{6}{|c|}{ 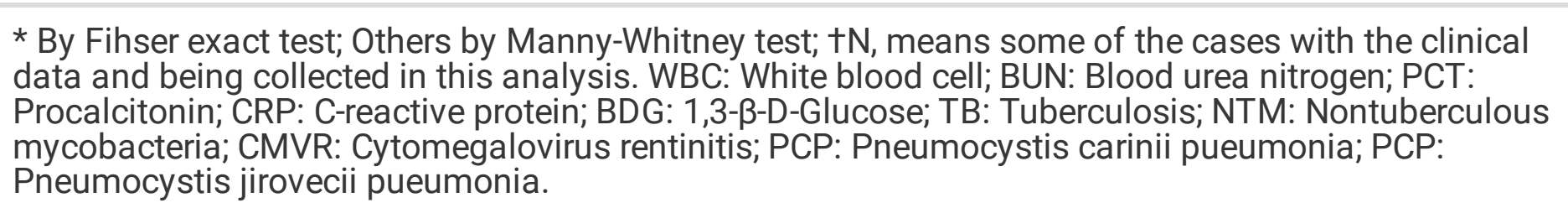 } \\
\hline
\end{tabular}

Risk factors for TM bloodstream infection patients with poor prognosis

Of the 87 cases in the study, 27 cases with incomplete data (CD4, CD8 count, PCT, albumin) were excluded, and 60 cases remained ( 11 with poor prognosis and 49 survival cases). The age, peripheral blood cells, serum albumin, CD4 count level, CD8 count level, and the time required for blood culture conversion, and the procalcitonin, 1,3-beta-D-glucan, and blood urea nitrogen levels of the patients were analyzed by logistic test for risk factors for poor prognosis. Univariate analysis showed that serum procalcitonin $(>0.60 \mathrm{ng} / \mathrm{mL})$, CD 8 count level $(<200 / \mu \mathrm{l}), 1,3$-beta-D-glucan $(<100 \mathrm{pg} / \mathrm{mL})$ and blood urea nitrogen level ( $>4 \mathrm{mmol} / \mathrm{L}$ ) were risk factors for poor prognosis. The above four factors were included in the multivariate analysis, and the results showed that the risk of poor prognosis was 12.6 times higher in patients with CD8 count $<200 / \mu \mathrm{l}$ than in those with CD8 count $>200 / \mu \mathrm{l}(p=0.04)$ and 34.9 times higher in those with 1,3-beta-D-glucan $<100 \mathrm{pg} / \mathrm{mL}$ than in those with 1,3-beta-D-glucan $>100 \mathrm{pg} / \mathrm{mL}(p=0.01)$ (See Table 2). 
Table 2

Logistic regression analysis of the risk factors for poor prognosis of patients with TM bloodstream infection

\begin{tabular}{|c|c|c|c|c|c|}
\hline Variable & $\begin{array}{l}\text { Crude odds } \\
\text { ratio (COR) }\end{array}$ & $\begin{array}{l}95 \% \text { confidence } \\
\text { interval (Cl) }\end{array}$ & $\begin{array}{l}\text { Adjusted odds } \\
\text { ratio (AOR) }\end{array}$ & $\begin{array}{l}95 \% \text { confidence } \\
\text { interval (Cl) }\end{array}$ & $\begin{array}{l}P \\
\text { value }\end{array}$ \\
\hline Years & Reference & - & & & \\
\hline$\geq 35$ years old & 1.15 & $0.31-4.28$ & & & \\
\hline WBC & Reference & - & & & \\
\hline$\geq 3.5^{\star} 10^{\wedge} 9 / \mathrm{L}$ & 0.8 & $0.22-2.97$ & & & \\
\hline $\mathrm{N}$ & Reference & - & & & \\
\hline$\geq 2 * 10^{\wedge} 9 / \mathrm{L}$ & 1.29 & $0.30-5.54$ & & & \\
\hline $\mathrm{Hb}$ & Reference & - & & & \\
\hline$\geq 90 \mathrm{~g} / \mathrm{L}$ & 0.44 & $0.12-1.67$ & & & \\
\hline PLT & Reference & - & & & \\
\hline$\geq 100 * 10^{\wedge} 9 / \mathrm{L}$ & 0.98 & $0.26-3.64$ & & & \\
\hline Albumin & Reference & - & & & \\
\hline$\geq 26 \mathrm{~g} / \mathrm{L}$ & 0.28 & $0.07-1.09$ & & & \\
\hline CD4 & Reference & - & & & \\
\hline$\geq 5 / \mathrm{ul}$ & 0.44 & $0.12-1.67$ & & & \\
\hline CRP & Reference & - & & & \\
\hline$\geq 65 \mathrm{mg} / \mathrm{L}$ & 3.01 & $0.77-11.73$ & & & \\
\hline $\begin{array}{l}\text { Culture } \\
\text { conversion } \\
\text { days }\end{array}$ & Reference & - & & & \\
\hline$\geq 6$ days & 0.24 & $0.04-1.27$ & & & \\
\hline РCT & Reference & - & Reference & - & - \\
\hline$\geq 0.60 \mathrm{ng} / \mathrm{mL}$ & 5.09 & $1.00-26.00$ & 8.47 & $0.55-129.41$ & 0.13 \\
\hline CD8 & Reference & - & Reference & - & - \\
\hline$<200 /$ ul & 6.53 & $1.27-33.46$ & 12.64 & $1.08-148.54$ & 0.04 \\
\hline $\begin{array}{l}\text { 1,3-B-D- } \\
\text { Glucose }\end{array}$ & Reference & -- & Reference & - & - \\
\hline
\end{tabular}

WBC: white blood cell; N: neutrophil; Hb: hemoglobin; PLT: Platelet; PCT, Procalcitonin; CRP: C-reactive protein; BUN: blood urea nitrogen 


\begin{tabular}{|llllll|}
\hline Variable & $\begin{array}{l}\text { Crude odds } \\
\text { ratio (COR) }\end{array}$ & $\begin{array}{l}95 \% \text { confidence } \\
\text { interval (Cl) }\end{array}$ & $\begin{array}{l}\text { Adjusted odds } \\
\text { ratio (AOR) }\end{array}$ & $\begin{array}{l}95 \% \text { confidence } \\
\text { interval (Cl) }\end{array}$ & $\begin{array}{l}\boldsymbol{P} \\
\text { value }\end{array}$ \\
\hline$<100 \mathrm{pg} / \mathrm{mL}$ & 4.68 & $1.18-18.51$ & 34.85 & $2.34-519.10$ & 0.01 \\
\hline BUN & Reference & - & Reference & - & - \\
\hline$\geq 4 \mathrm{mmol} / \mathrm{L}$ & 5.52 & $1.08-28.25$ & 2.4 & $0.30-19.00$ & 0.41 \\
\hline $\begin{array}{l}\text { WBC: white blood cell; N: neutrophil; Hb: hemoglobin; PLT: Platelet; PCT, Procalcitonin; CRP: C-reactive } \\
\text { protein; BUN: blood urea nitrogen }\end{array}$ & & & \\
\hline
\end{tabular}

The correlation between laboratory tests and the time to TM positive conversion in blood culture

Spearman correlation analysis was performed with the time to TM positive conversion in blood culture as the dependent variable and the levels of peripheral leukocytes, neutrophils, hemoglobin, platelets, albumin and PCT, and 1,3- $\beta$-D-glucan as independent variables. The results showed that the levels of both platelets $(r=0.37, p=0.0004)$ and albumin $(r=0.44, p<0.0001)$ were positively correlated with the time required for TM blood culture conversion, and the levels of PCT $(r=-0.40, p=0.0009)$ and 1,3- $\beta$-D-glucan $(r=-0.30, p=0.0076)$ were negatively correlated with the time required for TM positive in blood culture.

\section{Discussion}

The number of TM bloodstream infection cases among in-hospital patients increased from 2015 (13 cases) to 2019 (18 cases) at SPHCC. The rate of TM bloodstream infection among admitted patients increased from $0.99 \%$ in 2015 to $2.09 \%$ in 2020 (from January to July). According to a systematic review by Qin et al.[13], the estimated pooled prevalence of TM infection in China was 3.3\% (95\% Cl: 1.8-5.8\%), and the prevalence in Shanghai was 1.8\% (95\% Cl: 1.3-2.4\%), which are in line with our findings. As a referral center, we treat many kinds of opportunistic infections, including TM, and based on the etiology study of bloodstream infection among in-hospital patients in 2016[3], TM bloodstream infection accounted for $18.8 \%$ (43/299), which was the second most common bloodstream infection pathogen. With the progress of AIDS treatment and physician awareness of TM, reports of AIDS with TM infection have become increasingly common, and the prognosis depends on a timely diagnosis[19] and proper antifungal treatment[20, 21]. Immunodeficient patients from endemic areas should visit hospitals, and physicians should remain vigilant about TM symptoms and perform a specimen culture as early as possible and then initiate the antifungal regimen with Amphotericin B, Itraconazole or Voriconazole[21]. In this study, the mortality rate of patients with TM bloodstream infection was $17.2 \%$ (15/87), which is similar to 17.5\% (191/1093) published by Jiang et al in 2019[6] and 16.7\%[18] in our hospital from 2014 to 2015. In view of the fact that this is a single-center study from a tertiary hospital[22] where patients from all parts of the country obtain further diagnosis and treatment, it cannot represent all the patients with TM disease.

In this study, the admission blood urea nitrogen level, procalcitonin, and CRP in the poor prognosis group were significantly higher than those in the survival group; the peripheral blood CD8 count level and 1,3- $\beta$ - 
D-glucan level in the poor prognosis group were significantly lower than those in the survival group; in the overall presentation of patients with TM bloodstream infection, although they have extreme immunodeficiency, poor prognosis patients are often in an extremely severe inflammatory state and have poor nutritional status compared with the survival patients. As a result, the patient's condition still deteriorated with symptomatic support treatment, and eventually, the condition worsened or the patient even died within a few days after admission. Among the 15 cases of worsening illness or death in this study, the median length of hospital stay was only 5 days, which means that at the time of worsening illness or death, TM disease often had not been confirmed, which also indicates that the immunodeficiency caused by HIV infection requires early diagnosis and early intervention to avoid the development of severe immunodeficiency[23].

The presence of TM bloodstream infection is a predictor of severe immunodeficiency $[4,24]$. When they are in such an immunodeficient state, patients often have coinfection, such as cytomegalovirus retinitis, pulmonary TB, NTM disease, and cryptococcal meningitis.[22, 25]. There were fewer cases of coinfection in the group with poor prognosis. Considering that the group with poor prognosis had shorter overall hospitalization time and worsened or even died soon after admission, resulting in insufficient time for diagnosis, there may be missed diagnoses and fewer confirmed diseases than those in the group of surviving patients. Patients with poor prognosis are mostly in the late stage of the disease. Although they are given symptomatic supportive treatment after hospitalization, their condition fails to improve, and they lose the chance for antifungal treatment (or other comorbidities fail to control, and their condition is incurable). Therefore, the number of hospitalization days for patients with poor prognosis was significantly less than that of normal discharged patients.

In this study, risk factor analysis of patients with poor prognosis after clinical treatment for TM bloodstream infection showed that patients with CD8 count $<200 / \mu$ land whole blood 1,3-beta-D-glucan < $100 \mathrm{pg} / \mathrm{mL}$ had 12.6 times and 34.9 times the risk of poor prognosis, respectively. The median CD4 count was only $7 / \mu \mathrm{l}$, which belongs to the extremely immunodeficient population; the CD8 cell count was still significantly reduced, and the median count was only 202/ $\mu$ l. CD8 counts may predict prognosis independently of CD4 counts[26]. In most cases, HIV infection severely progresses, CD4 and CD8 are depleted[27]. This may explain why a delay in the diagnosis of TM independently predicted the early mortality of the patients[28, 29].

For the 1,3- $\beta$-D-glucan (BDG) level, this study found that those with a BDG less than $100 \mathrm{pg} / \mathrm{mL}$ are at risk for poor prognosis. This unexpected finding may be explained by the fact that late diagnosis is the main reason for the high mortality in TM-infected patients[30]. As mentioned previously, the BDG assay is helpful in the early detection of invasive fugal disease[31], including TM[32, 33]. The possible reason for this finding is that in clinical practice, using this marker as important evidence for fungal infection may cause delays in empirical diagnosis and treatment of patients with fever but low BDG levels; after all, blood culture results take time. Antifungal treatment may be initiated earlier in patients with high levels of BDG than in patients with low levels of BDG. Furthermore, in our analysis, when using the Spearman correlation, BDG was negatively correlated with the time required for blood culture to detect TM. 
There are some limitations of this study. First, because this is a retrospective analysis, the clinical data, such as treatment regimen administered before admission in our hospital, records of patients' visit experience, as well as the time from onset of symptoms to diagnosis, all affect the accuracy of descriptions and analysis. Second, this was a single-center study, and caution should be paid to making a summary or comparison with the population in areas with a high incidence of TM disease in China.

\section{Conclusions}

Bloodstream infections caused by TM are becoming increasingly common in the AIDS population with severe immunodeficiency in East China. For those with extremely low CD 4 and CD8 cell counts below $200 / \mathrm{ul}$, the $1,3-\beta$-D-glucan $<100 \mathrm{pg} / \mathrm{mL}$ are with an increased risk of poor prognosis. Improving the awareness of symptoms such as umbilical fovea rash, fever and lymphadenopathy has a positive effect on early diagnosis of the disease and optimization of treatment efficacy.

\section{Abbreviations}

TM: Talaromyces marneffei; HIV: Human immunodeficiency virus; AIDS: Acquired immunodeficiency syndrome; WBC: White blood cell; BUN: Blood urea nitrogen; PCT: Procalcitonin; CRP: C-reactive protein;

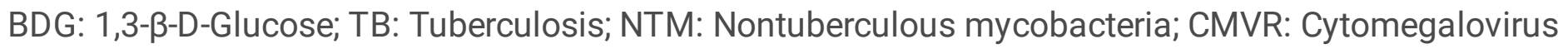
rentinitis; PCP: Pneumocystis jirovecii pueumonia.

\section{Declarations}

Ethics approval and consent to participate

Ethical approval was granted by the Ethics Committee of Shanghai Public Health Clinical Center (Ethics approval No. 2017-S022-04). This study used retrospective and anonymous data collection methods, which did not involve patient privacy, so informed consent was exempted from ethical review.

Consent for publication Not applicable.

Availability of data and materials

All data generated or analyzed during this study are included in this published article and its supplementary information files(S1 File).

Competing interests The authors declare that they have no competing interests.

Funding This study was supported by the grant of National Major Scientific and Technological Special Project for 'Significant New Drugs Development-Scientific and Technological Platform Construction for New Anti-HIV Drugs Clinical Assessment during the Thirteenth Five-year Plan Period (2017ZX09304027) and the Clinical Research Support Project of SPHCC (No: KY-GW-2020-30). The funders had no role in study design, data collection and analysis, decision to publish, or preparation of the manuscript. 
Authors' contributors HZL, JJS and WWS conceived and designed the study; JJS and WWS, YT, RFZ,LL,YZS,JRW,JC,ZYW,WS,TKQ and SBX, YXL collected the data. JJS, WWS and YT,

RFZ,LL,YZS,JRW,JC analyzed the data; JJS, WWS and HZL interpreted the results; JJS wrote the first draft; JJS, WWS, HZL, RFZ, LL,YZS, JRW, JC, ZYW,WS,TKQ, YT,SBX and YXL contributed to the final version. All authors have read and approved the manuscript.

Acknowledgments We extend our thanks to the colleagues of HIV health care clinic and the staff in the Department of Infection and Immunity, Shanghai Public Health Clinical Center.

\section{References}

1. Jones PD, See J. Penicillium marneffei infection in patients infected with human immunodeficiency virus: late presentation in an area of nonendemicity. Clin Infect Dis 1992;15:744.

Doi:10.1093/clind/15.4.744.

2. Kaplan JE, Hu DJ, Holmes KK, Jaffe HW, Masur H, De Cock KM. Preventing opportunistic infections in human immunodeficiency virus-infected persons: implications for the developing world. Am J Trop Med Hyg 1996;55:1-11.

3. Qi T, Zhang R, Shen Y, Liu L, Lowrie D, Song W et al. Etiology and clinical features of 229 cases of bloodstream infection among Chinese HIV/AIDS patients: a retrospective cross-sectional study. Eur J Clin Microbiol Infect Dis 2016;35:1767-70. Doi:10.1007/s10096-016-2724-7.

4. Supparatpinyo K, Khamwan C, Baosoung V, Nelson KE, Sirisanthana T. Disseminated Penicillium marneffei infection in southeast Asia. Lancet 1994;344:110 - 13. Doi:10.1016/s01406736(94)91287-4.

5. Ranjana KH, Priyokumar K, Singh TJ, Gupta C, Sharmila L, Singh PN et al. Disseminated Penicillium marneffei infection among HIV-infected patients in Manipur state, India. J Infect 2002;45:268 - 71. Doi:10.1053/jinf.2002.1062.

6. Jiang J, Meng S, Huang S, Ruan Y, Lu X, Li JZ et al. Effects of Talaromyces marneffei infection on mortality of HIV/AIDS patients in southern China: a retrospective cohort study. Clin Microbiol Infect 2019;25:233 - 41. Doi:10.1016/j.cmi.2018.04.018.

7. Cao C, Xi L, Chaturvedi V. Talaromycosis (Penicilliosis) Due to Talaromyces (Penicillium) marneffei: Insights into the Clinical Trends of a Major Fungal Disease 60 Years After the Discovery of the Pathogen. Mycopathologia 2019;184:709 - 20. Doi:10.1007/s11046-019-00410-2.

8. Deng ZL, Connor DH. Progressive disseminated penicilliosis caused by Penicillium marneffei. Report of eight cases and differentiation of the causative organism from Histoplasma capsulatum. Am J Clin Pathol 1985;84:323 - 27. Doi:10.1093/ajcp/84.3.323.

9. Hien TV, Loc PP, Hoa NT, Duong NM, Quang VM, Mcneil MM et al. First cases of disseminated penicilliosis marneffei infection among patients with acquired immunodeficiency syndrome in Vietnam. Clin Infect Dis 2001;32:e78-80. Doi:10.1086/318703. 
10. Hu Y, Zhang J, Li X, Yang Y, Zhang Y, Ma J et al. Penicillium marneffei infection: an emerging disease in mainland China. Mycopathologia 2013;175:57-67. Doi:10.1007/s11046-012-9577-0.

11. Chastain DB, Henao-Martinez AF, Franco-Paredes C. Opportunistic Invasive Mycoses in AIDS: Cryptococcosis, Histoplasmosis, Coccidiodomycosis, and Talaromycosis. Curr Infect Dis Rep 2017;19:36. Doi:10.1007/s11908-017-0592-7.

12. Zhou LH, Jiang YK, Li RY, Huang LP, Yip CW, Denning DW et al. Risk-Based Estimate of Human Fungal Disease Burden, China. Emerg Infect Dis 2020;26:2137-47. Doi:10.3201/eid2609.200016.

13. Qin Y, Huang X, Chen H, Liu X, Li Y, Hou J et al. Burden of Talaromyces marneffei infection in people living with HIV/AIDS in Asia during ART era: a systematic review and meta-analysis. Bmc Infect Dis 2020;20:551. Doi:10.1186/s12879-020-05260-8.

14. Qiu Y, Zeng W, Zhang H, Zhong X, Tang S, Zhang J. Comparison of pleural effusion features and biomarkers between talaromycosis and tuberculosis in non-human immunodeficiency virus-infected patients. Bmc Infect Dis 2019;19:745. Doi:10.1186/s12879-019-4376-6.

15. Tsang CC, Lau S, Woo P. Sixty Years from Segretain's Description: What Have We Learned and Should Learn About the Basic Mycology of Talaromyces marneffei? Mycopathologia 2019;184:721 - 29. Doi:10.1007/s11046-019-00395-y.

16. Kawila R, Chaiwarith R, Supparatpinyo K. Clinical and laboratory characteristics of penicilliosis marneffei among patients with and without HIV infection in Northern Thailand: a retrospective study. Bmc Infect Dis 2013;13:464. Doi:10.1186/1471-2334-13-464.

17. Li Q, Wang C, Zeng K, Peng X, Wang F. AIDS-associated disseminated talaromycosis (penicilliosis) marneffei. J Dtsch Dermatol Ges 2018;16:1256-59. Doi:10.1111/ddg.13663.

18. Chen J, Zhang R, Shen Y, Liu L, Qi T, Wang Z et al. Clinical Characteristics and Prognosis of Penicilliosis Among Human Immunodeficiency Virus-Infected Patients in Eastern China. Am J Trop Med Hyg 2017;96:1350-54. Doi:10.4269/ajtmh.16-0521.

19. Li X, Zheng Y, Wu F, Mo D, Liang G, Yan R et al. Evaluation of quantitative real-time PCR and Platelia galactomannan assays for the diagnosis of disseminated Talaromyces marneffei infection. Med Mycol 2020;58:181 - 86. Doi:10.1093/mmy/myz052.

20. Lau S, Xing F, Tsang CC, Tang J, Tan YP, Ye H et al. Clinical characteristics, rapid identification, molecular epidemiology and antifungal susceptibilities of Talaromyces marneffei infections in Shenzhen, China. Mycoses 2019;62:450 - 57. Doi:10.1111/myc.12887.

21. Lei HL, Li LH, Chen WS, Song WN, He Y, Hu FY et al. Susceptibility profile of echinocandins, azoles and amphotericin B against yeast phase of Talaromyces marneffei isolated from HIV-infected patients in Guangdong, China. Eur J Clin Microbiol Infect Dis 2018;37:1099 - 102.

Doi:10.1007/s10096-018-3222-x.

22. Luo B, Sun J, Cai R, Shen Y, Liu L, Wang J et al. Spectrum of Opportunistic Infections and Risk Factors for In-Hospital Mortality of Admitted AIDS Patients in Shanghai. Medicine (Baltimore) 2016;95:e3802. Doi:10.1097/MD.0000000000003802. 
23. Sun J, Liu L, Shen J, Chen P, Lu H. Trends in baseline CD4 cell counts and risk factors for late antiretroviral therapy initiation among HIV-positive patients in Shanghai, a retrospective crosssectional study. Bmc Infect Dis 2017;17:285. Doi:10.1186/s12879-017-2398-5.

24. Sirisanthana T, Supparatpinyo K. Epidemiology and management of penicilliosis in human immunodeficiency virus-infected patients. Int J Infect Dis 1998;3:48-53. Doi:10.1016/s12019712(98)90095-9.

25. Xiao J, Gao G, Li Y, Zhang W, Tian Y, Huang Y et al. Spectrums of Opportunistic Infections and Malignancies in HIV-Infected Patients in Tertiary Care Hospital, China. Plos One 2013;8:e75915. Doi:10.1371/journal.pone.0075915.

26. Cao W, Mehraj V, Kaufmann DE, Li T, Routy JP. Elevation and persistence of CD8 T-cells in HIV infection: the Achilles heel in the ART era. J Int Aids Soc 2016;19:20697.

Doi:10.7448/IAS.19.1.20697.

27. Helleberg M, Kronborg G, Ullum H, Ryder LP, Obel N, Gerstoft J. Course and Clinical Significance of CD8 + T-Cell Counts in a Large Cohort of HIV-Infected Individuals. J Infect Dis 2015;211:1726-34. Doi:10.1093/infdis/jiu669.

28. Zheng J, Gui X, Cao Q, Yang R, Yan Y, Deng L et al. A Clinical Study of Acquired Immunodeficiency Syndrome Associated Penicillium Marneffei Infection from a Non-Endemic Area in China. Plos One 2015;10:e130376. Doi:10.1371/journal.pone.0130376.

29. Li Y, Lin Z, Shi X, Mo L, Li W, Mo W et al. Retrospective analysis of 15 cases of Penicillium marneffei infection in HIV-positive and HIV-negative patients. Microb Pathog 2017;105:321 - 25.

Doi:10.1016/j.micpath.2017.01.026.

30. Qiu Y, Zhang JQ, Pan ML, Zeng W, Tang SD, Tan CM. Determinants of prognosis in Talaromyces marneffei infections with respiratory system lesions. Chin Med J (Engl) 2019;132:1909-18. Doi:10.1097/CM9.0000000000000345.

31. Lahmer T, Held J, Rasch S, Schnappauf C, Beitz A, Schmid RM et al. Usage of 1,3-beta-D-Glucan for Early Detection of Invasive Mycoses and Outcome Parameter in Immunocompromised Critically III Patients. Mycopathologia 2016;181:815 - 21. Doi:10.1007/s11046-016-0061-0.

32. Farhour Z, Mehraj V, Chen J, Ramendra R, Lu H, Routy JP. Use of (1->3)-beta-d-glucan for diagnosis and management of invasive mycoses in HIV-infected patients. Mycoses 2018;61:718 - 22. Doi:10.1111/myc.12797.

33. Yoshimura Y, Sakamoto Y, Lee K, Amano Y, Tachikawa N. Penicillium marneffei Infection with beta-Dglucan Elevation: A Case Report and Literature Review. Intern Med 2016;55:2503-06.

Doi:10.2169/internalmedicine.55.6173.

\section{Supplementary Files}

This is a list of supplementary files associated with this preprint. Click to download. 
- supplementdata.xls

Page 15/15 